\title{
How to encourage innovation failure knowledge sharing in virtual research organization: an incentive mechanism based on game theory
}

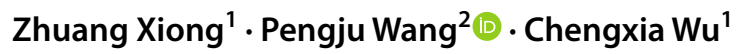

Accepted: 17 November 2020 / Published online: 12 January 2021

(c) The Author(s) 2020

\begin{abstract}
Innovation failure knowledge sharing plays an important role in reducing the probability of repeated failure of subsequent innovation and improving innovation ability of virtual research organization. However, it is very difficult for members to actively share the innovation failure knowledge without incentives. To promote the sharing behavior of innovation failure knowledge in virtual research organization, by using game theory, considering the risk aversion degree of members and the negative effect of fault-tolerance environment, the incentive model of innovation failure knowledge sharing of virtual research organization was constructed, the incentive relationship of innovation failure knowledge sharing between organization and its members under the influence of different states was analyzed, and the theoretical model was simulated and verified through a case study from China. Results show that: (1) without considering the negative effect of fault-tolerant environment, the optimal incentive coefficient of innovation failure knowledge sharing is positively related to the shareable rate and the transformation ability of innovation failure knowledge of members, and negatively related to the sharing cost and risk aversion degree of members; (2) considering the negative effect of fault-tolerant environment, virtual research organization should make a corresponding modification of sharing incentive intensity according to the estimation of tolerance degree to fault-tolerant environment by itself and its members, so as to reduce the knowledge input of organization. The findings obtained from this study provide a novel idea and method for the design of incentive mechanism of innovation failure knowledge sharing of virtual research organization.
\end{abstract}

Keywords Virtual research organization - Innovation failure knowledge $\cdot$ Knowledge sharing $\cdot$ Incentive mechanism $\cdot$ Fault-tolerant environment $\cdot$ Game theory

Pengju Wang

wangpengju1986@zut.edu.cn

Extended author information available on the last page of the article 


\section{Introduction}

In the era of knowledge economy, innovation agents can effectively improve their innovation ability through knowledge sharing in the process of innovation (Prester and Jurić 2019). However, the process of knowledge sharing is affected by many factors such as knowledge-sharing agent, knowledge-sharing environment and knowledge-sharing medium (Ghobadi 2015; Weller 2017; Safari et al. 2018), which makes knowledge sharing become one of the problems faced by knowledge management of innovative organizations (Liu et al. 2020). Especially in the increasingly fierce and complex competitive environment, more and more innovation agents strengthen their agility of market opportunity response, core competence of enterprises and speed of collaborative innovation through the organizational form of alliance network (Dickson and Weaver 2011; Standing and Standing 2018), which further increases the difficulty of knowledge sharing among innovation agents. Meanwhile, virtual research organization, represented by virtual laboratory, virtual community and virtual research teams, has become an important organizational form for innovation agents to form R\&D network alliances in the information age. Some successful cases, such as CSBI (Computing Systems Biology Initiative) in Massachusetts Institute of Technology, and nanoHUB project of Purdue University, have proved the advantages of virtual research organizations (Chen et al. 2019). However, the characteristics of uncertainty, dispersion and complexity of knowledge make virtual research organizations have difficulties in knowledge sharing. The successful diffusion of virtual research mode largely benefits from the efficient knowledge sharing among internal members (Dawes et al. 2012). Therefore, there is still a widespread concern that how to improve the efficiency of knowledge sharing in virtual research organization and promote knowledge-sharing behavior among members.

Virtual research organization is a cooperative R\&D organization established by multiple independent R\&D agents centering on the common goal, using highly developed modern information, communication and transportation technology, breaking the time and regional restrictions, and realizing the complementarity and sharing of resources such as equipment, capital, technology and talents under the network innovation paradigm characterized by the integration of technological resources and organizations (Dai and $\mathrm{Hu} 2011$ ). Theory and practice found that through the integration and sharing of knowledge resources among member enterprises, virtual research organization improved the efficiency of R\&D resources utilization and knowledge value efficiency (Davenport and Daellenbach 2011), became the endogenous factor of its innovation ability improvement, and was the foundation of continuous innovation of virtual research organization (Del Baldo and Baldarelli 2017). However, due to an anti-failure bias (McGrath 1999), innovation failure has not attracted widespread attention in traditional innovation research and practice. In particular, knowledge resources contained in innovation failure have not become the focus of knowledge sharing in virtual research organization. In the process of innovation, failure events are inevitable and objective. By analyzing and identifying failure events, learning from failure experience 
can acquire more knowledge than learning from success experience (Desai 2015). It can be seen that failure knowledge is an important resource in organizational learning, which can help enterprises reduce the probability of repeated failure and further improve enterprise performance (Shepherd 2003). Therefore, within the virtual research organization, the sharing of innovation failure knowledge among members plays an important role in improving the collaborative innovation ability of the organization.

However, innovation failure knowledge is the learning and transformation of members' previous experience of innovation failure, the differences in learning ability and knowledge transformation ability of members may lead to the difficulty in expressing the innovation failure knowledge and the high cost of transformation and sharing (Wang 2017). In addition, under the influence of anti-failure bias, the sharing of innovation failure knowledge among organizational members may also cause organizations and other members to question their innovation ability to achieve success. Especially in the virtual research organizations, due to there is no strong relationship between members, the problem that questioning members' ability caused by failure bias may be more prominent, which not only affects the collaborative innovation relationship between members, but also makes knowledge sharers be received different treatment in organization status and resource allocation (Xiong et al. 2020).

Therefore, different from the intensive knowledge management of traditional research organizations, the negative effects of innovation failure become a potential constraint to the knowledge sharing of virtual research organizations. In the absence of effective incentive mechanism, the sharing of innovation failure knowledge is difficult to form spontaneously within the organization. How to encourage the sharing willingness of the members of virtual research organization becomes the key to solve the challenges in the sharing of innovation failure knowledge.

The remaining structure of this paper is as follows: Sect. 2 reviews the literatures on virtual research organization, innovation failure knowledge and knowledge sharing incentive. Section 3 constructs an incentive model based on the game relationship between virtual research organization and members, and describes the theoretical model. Section 4 analyzes and discusses the change of the optimal incentive coefficient of innovation failure knowledge sharing with the influence of the negative effect of fault-tolerance environment, and carries out the model simulation according to the calculation results of the model. Section 5 draws the conclusions obtained from this study.

\section{Literature review}

Compared with the traditional technology and product development model, virtual research organization has significant advantages in promoting organizational learning among members, improving innovation ability and reducing R\&D cost (Adler and Zirger 1998). As soon as the concept of virtual and networked organization is put forward, it is widely used in innovation practice, and the cooperative innovation effect of virtual research organization is also concerned. Due to the traditional supervision and control are costly, even ineffective (Liu et al. 2017). In practice, 
more and more innovation agents realize that the trust relationship among members is the most important condition for the success of virtual research organization (Albers et al. 2016; Raghuram et al. 2019). Therefore, in the operation and management of virtual research organization, the corresponding trust mechanism, coordination mechanism, incentive mechanism, distribution mechanism and decision-making mechanism need to be established to ensure the successful operation of virtual research organization (Luo et al. 2010). Moreover, due to the learning effect in the process of knowledge sharing, virtual research organization can effectively selfmotivate under certain conditions.

Theorists and practitioners are also increasingly aware of the important resources contained in innovation failure events in innovation practice. The innovation organization can reduce the probability of similar failure in the future and improve the organization's innovation performance by exploring and learning the failure experience and adjusting the way of behavior in subsequent innovation. Carmeli and Dothan (2017) found that moderate failure can stimulate enterprises to find solutions to problems. According to the findings of Deichmann and Ende (2013) and Yu and $\mathrm{Pu}$ (2018), learning from failure can transfer knowledge and generate new knowledge, which has a positive effect on innovation performance. It is not hard to see that failure knowledge refers to some potential knowledge and skills to improve organizational performance acquired by innovative organizations in the exploration and learning from failure experience. It is learned from three parts: failure identification, failure analysis and failure handling (Cannon and Edmondson 2001). Amankwah Amoah et al. (2018) believed that the accumulation of failure resources by innovation organizations can improve and enrich the skills and knowledge extremely useful for subsequent innovation activities. Kim and Miner (2007) found that in order to adapt to the changes and innovation of the external environment. Failure knowledge plays an important role. In innovation studies, most scholars prefer to learn from successful enterprises, thus neglecting the learning and knowledge transformation of failure experience (Chen et al. 2017). But when enterprises absorb new knowledge and expect future outcomes, Lin et al. (2019) believed that learning from failure is as important and effective as learning from success. Failure learning is of great help to the improvement of organizational innovation capability (Assaad and El-Adaway 2020) and coping with organizational crisis (Rhaiem and Amara 2019), and through the analysis of failure experience, enterprises can launch more innovative new products (Danneels and Vestal 2020). Especially with the increasing intensity of market competition, it is difficult for enterprises to maintain their own sustainable competitive advantage by independently carrying out innovation activities (Al-Haddad and Whittington 2019). By using dynamic organizational forms such as virtual research organization and supply chain alliance, resource sharing among innovative enterprises can be realized, and then knowledge collaborative innovation of enterprises can be promoted (Connell et al. 2014). Through failure knowledge sharing, the continuous innovation ability of innovative enterprises can be improved, and the probability of innovation success can be provided (Wang 2017; Xiong et al. 2016). Compared with the knowledge innovation of a single enterprise, knowledge innovation between enterprises connected in the form of dynamic organization can provide more and more valuable knowledge resources. 
However, due to the non-coding and complexity of knowledge and many inherent obstacles in the process of knowledge sharing (Razmerita et al. 2016; Almeida et al. 2018), the phenomenon of active knowledge sharing by member enterprises without incentives seldom occurs. In addition, knowledge itself is difficult to measure its external characteristics (Ma and Chan 2014), which makes it difficult to accurately monitor the level of knowledge sharing efforts. Member enterprises are prone to free riding in knowledge sharing activities, which affect the overall operational efficiency of the organization and undermine the coordination of the organization (Yu 2018). Therefore, how to design incentive mechanism to promote knowledge sharing of member enterprises under the condition of asymmetric information has attracted attention. Incentive can effectively increase team knowledge sharing behavior (Siemsen et al. 2007). There are also differences in the promotion effect of different incentive methods on knowledge sharing. Compared with the technical support, the effect of material incentive is more obvious (Zhang and Zhang 2014), especially the compensation incentive can promote knowledge sharing (Choi et al. 2008). Moreover, the effect of incentive methods is often affected by many factors. Xie and Liu (2014) constructed and tested the theoretical framework of knowledge sharing incentive mechanism based on multi theory and multi factor perspective by integrating economic, social and psychological theories. Nan (2008) classified knowledge according to its intangibility, and constructed an incentive model for sharing different types of knowledge under the condition of asymmetric information. The structure change of reward system has a significant impact on tacit knowledge sharing behavior. When the reward intensity or sharing cost reaches some critical value, tacit knowledge sharing behavior will be substantially improved (Jiang and Xu 2020).

Furthermore, studies have found that the differences of individual characteristics of knowledge sharing agents are the factors that cannot be ignored. Wang and Shao (2012) considered the complementarity of knowledge, and designed incentive contracts of agent risk neutral and risk averse under the framework of principal-agent theory. Liu et al. (2015) proposed a knowledge sharing incentive model of e-commerce service supply chain from the perspective of knowledge complementarity and knowledge integration ability. Friedrich et al. (2020) designed a feasible incentive approach of employee knowledge sharing behavior in knowledge management systems by using game mechanism from aspects of human motivation and the individual willingness to knowledge sharing.

Through the review of the above literatures, it can be found that the failure knowledge management has attracted attention, and the incentive mechanism of knowledge sharing among members in different forms of alliance organization has been discussed. However, there are still some deficiencies in previous studies of how to share and encourage the failure knowledge, mainly in the following aspects: (1) compared with the particularity of general knowledge resources, the sharing process of failure knowledge is more difficult and complex. In addition to the influence of common factors such as knowledge stock, absorptive capacity and trust relationship between the sharing parties, the cognitive attitude of organizational members to innovation failure events is an important factor affecting the sharing of failure knowledge. But most of the existing studies focus on how to identify and analyze the failure knowledge from the failure experience (Edmondson 2011), and less on 
how to share it. (2) Although some studies have found that failure knowledge sharing has a significant positive effect on improving the organization's ability of continuous innovation and the probability of innovation success (Zhang 2019), ignoring the impacts of fault-tolerant environment on the willingness of knowledge sharing among members, and the incentive mechanism of failure knowledge sharing needs to be further explored. (3) The design of knowledge sharing incentive mechanism based on principal-agent theory ignores the negative effect of fault-tolerant environment, but in the virtual research organization with relatively loose organizational structure, the problem of negative effect may be more prominent, and the incentive mechanism of innovation failure knowledge sharing may have its own uniqueness.

Therefore, to fill in the shortcomings of the above studies, the incentive model of innovation failure knowledge sharing of virtual research organization was constructed in this study, and the incentive mechanism forms under the situation of negative utility influence and no influence of fault-tolerant environment were compared, so as to provide reference for the design of incentive mechanism of innovation failure knowledge sharing of virtual research organization.

\section{Modelling}

Learning and sharing innovation failure knowledge can effectively improve the innovation ability of virtual research organization. The quantity and quality of innovation failure knowledge sharing depend on each member's ability of knowledge transformation, the willingness of knowledge sharing, and the incentive intensity of virtual research organization. Thus, a game relationship about innovation failure knowledge sharing is formed between virtual research organization and its members. According to the existing findings (Wang and Shao 2012; Liu et al. 2015; Wang 2017) and expectancy theory of motivation (Lloyd and Merten 2018), further, it is assumed that a member of virtual research organization has innovation failure. Its knowledge transformation ability of innovation failure is $x$, the effort level of innovation failure knowledge sharing is $\Delta e$, the cost of innovation failure knowledge sharing is $C(\Delta e)$, and the benefit of innovation failure knowledge sharing among members to virtual research organization is $R(\Delta e, x)$. To encourage members to share the innovation failure knowledge, virtual research organization will reward the members of innovation failure knowledge sharing by incentive fee $S$. At this time, the game strategies of innovation failure knowledge sharing between virtual research organization and its members are: virtual

Table 1 The income matrix of the game parties under different strategies

\begin{tabular}{lll}
\hline $\begin{array}{l}\text { Virtual research } \\
\text { organization }\end{array}$ & Organization member & \\
\cline { 2 - 3 } & Sharing & No sharing \\
\hline Incentive & $R(\Delta e, x)-S, S-C(\Delta e)$ & $-S, S$ \\
No incentive & $R(\Delta e, x),-C(\Delta e)$ & 0,0 \\
\hline
\end{tabular}

Source: Created by the authors 
research organization $=\{$ incentive, no incentive $\}$, organization member $=\{$ sharing, no sharing $\}$. It can be seen that the income matrix of the game parties under different strategies is shown in Table 1.

From the results in Table 1, it can be seen that the optimal strategy of virtual research organization is not to encourage the failure knowledge sharing behavior of its members, while the optimal strategy of its members is not to share the failure knowledge. The implementation of the above-mentioned game strategies often leads to the problem of adverse selection between virtual research organization and its members, weakens the communication and information sharing among members, to a certain extent, affects the flow of failure knowledge among members, and reduces the overall innovation output and innovation ability improvement of virtual research organization. Therefore, virtual research organization needs effective incentive mechanism to promote the failure knowledge sharing among organization members. Through learning of innovation failure knowledge by organization members, the innovation ability of virtual research organization can be improved and the probability of innovation failure can be reduced.

Further, when a member of virtual research organization has a certain amount of innovation failure knowledge, but because the innovation failure knowledge is the transformation of previous failure experience, there is a certain degree of private ownership of innovation failure knowledge for members, and organization members do not share all innovation failure knowledge, $q(0 \leq q \leq 1)$ is the shareable rate of innovation failure knowledge of organization members. The higher the shareable rate $q$ is, the more innovation failure knowledge that organization member can share, the easier it is to share. Innovation failure knowledge stock $K(x)$ owned by organization members is a function of their own innovation failure knowledge transformation ability $x$. According to the expression of Cobb-Douglas production function (Chang and Ahn 2005), the growth mode of innovation failure knowledge stock of members is as follows:

$$
K=x M^{a}
$$

where $K$ is the innovation failure knowledge stock of members. $M$ is the loss of innovation failure of members. $a$ is the output elasticity coefficient of innovation failure knowledge.

In addition, it is assumed that $b(0 \leq b \leq 1)$ is the sharing cost coefficient of innovation failure knowledge of members. $S(R)$ is the optimal incentive contract that virtual research organization gives to its members, and $R$ is the benefit that failure knowledge sharing brings to virtual research organization.

Specifically: (1) the income function $R(\Delta e, x)$ of failure knowledge sharing is a linear function of the sharing effort $\Delta e$ and the transformation ability of failure knowledge $x$, namely:

$$
R(\Delta e, x, \varepsilon)=q\left(x M^{a}\right) \Delta e+\varepsilon
$$

where $\varepsilon$ is an exogenous random variable, and $\varepsilon \sim N\left(\mu, \sigma^{2}\right)$.

(2) The sharing cost function of innovation failure knowledge of members is as follows: 


$$
C(\Delta e)=b \Delta e^{2} / 2
$$

(3) Refer to the findings of Wu and Zhang (2016), it is assumed that the optimal incentive contract of virtual research organization includes two parts: one is the basic income of members; the other is the incentive income of members, which is related to the sharing income of innovation failure knowledge of virtual research organization. $\beta$ is the sharing incentive coefficient of innovation failure knowledge. Therefore, the optimal incentive contract $S(R)$ given to members by virtual research organization can be expressed as:

$$
S(R)=\alpha+\beta R(\Delta e, x, \varepsilon)
$$

In addition, according to the findings of Xiong et al. (2020) and Hao et al. (2019), the previous failure experience of innovation agents often has a negative impact on their subsequent innovation decisions, which makes innovation failure agents excessively enlarge the risk perception of re-innovation. Therefore, in the context of innovation failure knowledge sharing among members of virtual research organization, it is further assumed that members are risk averse, and its utility function is expressed as follows:

$$
U(W A)=-e^{-\rho W A}
$$

where $\rho$ is the absolute risk aversion coefficient, $W A$ represents the expected income of members. At the same time, the risk cost of members is $\rho \operatorname{var}(s) / 2=\rho \beta^{2} \alpha^{2} / 2$, which indicates that members are willing to pay $\rho \beta^{2} \alpha^{2} / 2$ in return for the deterministic utility. Assuming that the virtual research organization is risk neutral, its expected utility is equal to the expected income. At this time, the expected income and expected utility of virtual research organization are as follows:

$$
\begin{gathered}
\text { Wvro }=R(\Delta e, x, \varepsilon)-S(R)=-\alpha+(1-\beta)\left(q x M^{a} \Delta e+\varepsilon\right) \\
U(\text { Wvro })=-\alpha+(1-\beta)\left(q x M^{a} \Delta e+\mu\right)
\end{gathered}
$$

The expected income and expected utility of members are as follows:

$$
\begin{gathered}
W A=S(R)-C(\Delta e)=\alpha+\beta\left(q x M^{a} \Delta e+\varepsilon\right)-b \Delta e^{2} / 2 \\
U(W A)=\alpha+\beta\left(q x M^{a} \Delta e+\mu\right)-b \Delta e^{2} / 2-\rho \beta^{2} \sigma^{2} / 2
\end{gathered}
$$

From the perspective of virtual research organization, it hopes that more members can share the innovation failure knowledge, so as to improve the innovation ability of the organization and reduce the probability of innovation failure, and yet the members will pay more attention to the maximization of their own utility. Therefore, when considering the conditions of participation constraint (PC) and incentive constraint (IC), the incentive model of innovation failure knowledge sharing is as follows: 


$$
\begin{gathered}
\max _{\alpha, \beta, x, \Delta e} U(\text { Wvro })=-\alpha+(1-\beta)\left(q x M^{a} \Delta e+\mu\right) \\
\text { s.t. }\left\{\begin{array}{l}
(P C) \quad \alpha+\beta\left(q x M^{a} \Delta e+\mu\right)-b \Delta e^{2} / 2-\rho \beta^{2} \sigma^{2} / 2 \geq \bar{u} \\
(I C) \quad \Delta e^{*} \in \operatorname{argmax}\left[\alpha+\beta\left(q x M^{a} \Delta e+\mu\right)-b \Delta e^{2} / 2-\rho \beta^{2} \sigma^{2} / 2\right]
\end{array}\right.
\end{gathered}
$$

In virtual research organization, information asymmetry is often found between the organization and members. Under the condition of incomplete information, it is difficult for virtual research organization to accurately observe the sharing efforts of innovation failure knowledge of members, but it can measure the transformation ability of innovation failure knowledge by judging the innovation ability of members, and it can also observe the output income of innovation failure knowledge sharing. The output income is determined by the sharing efforts of innovation failure knowledge of members and exogenous random variables.

Therefore, when the model parameters $x, \alpha$ and $\beta$ are determined, the incentive constraint (IC) of innovation failure knowledge sharing can be expressed as:

$$
\max _{\Delta e} U(W A)=\max _{\Delta e}\left[\alpha+\beta\left(q x M^{a} \Delta e+\mu\right)-b \Delta e^{2} / 2-\rho \beta^{2} \sigma^{2} / 2\right]
$$

The first derivative of parameter $\Delta e$ is obtained from formula (12), which is equivalent to the maximization of the deterministic income of innovation failure knowledge sharing of members.

$$
\text { (IC) } \Delta e=\beta q x M^{a} / b
$$

On above basis, the conditions of participation constraint (PC) and incentive constraint (IC) are introduced into the objective function, and the following results are obtained:

$$
\max _{\beta} U(\text { Wvro })=-\bar{u}-\beta^{2} q^{2} x^{2} M^{2 a} / 2 b+\beta q^{2} x^{2} M^{2 a} / b-\rho \beta^{2} \sigma^{2} / 2+\mu
$$

In the above objective function, the first derivative of $\beta$ is calculated, namely:

$$
\partial U(W v r o) / \partial \beta=-\beta q^{2} x^{2} M^{2 a} / b+q^{2} x^{2} M^{2 a} / b-\rho \beta \sigma^{2}=0
$$

Obtain:

$$
\begin{gathered}
\beta^{*}=q^{2} x^{2} M^{2 a} /\left(b \rho \sigma^{2}+q^{2} x^{2} M^{2 a}\right) \\
\Delta e^{*}=q^{3} x^{3} M^{3 a} /\left(b^{2} \rho \sigma^{2}+b q^{2} x^{2} M^{2 a}\right)
\end{gathered}
$$

According to the findings of Zhang et al. (2019), the fault-tolerant environment for innovation failure will affect the innovation agents' correct understanding of previous innovation failure, and negatively affect their subsequent innovation decisions. Therefore, fault-tolerant environment may also be an important exogenous factor that affects the innovation failure knowledge sharing of virtual research organization. In fact, the tolerance degree of fault-tolerant environment in virtual research organization is often difficult to observe, which can only be described by the prior 
probability of subjective attitude of virtual research organization and its members. That is to say, when the members are at the same sharing efforts of innovation failure knowledge, the more tolerant the organization's internal fault-tolerant environment is, the more able the members can correctly understand each other's previous innovation failure, actively learn from the failure experience, and will not question the innovation ability of the partners and affect each other's innovation collaboration because of the previous innovation failure, so that the innovation failure knowledge sharing has a better effect. However, if there is a negative fault-tolerant environment in the virtual research organization, it will have a more obvious negative effect on the sharing efforts of innovation failure knowledge of members. In the above analysis process, the exogenous random variables including fault-tolerant environment are assumed to be observable. It is necessary to consider the impact of fault-tolerant environment on the sharing efforts of innovation failure knowledge of members, and further assume that the sharing cost function of innovation failure knowledge of members is as follows:

$$
C=b(\Delta e-r \varepsilon)^{2} / 2
$$

where $r$ is the impact degree of fault-tolerant environment in virtual research organization, and $0<r<1$. If $r=0$, it is the sharing cost of members under the ideal condition without considering the negative effect of fault-tolerant environment. Furthermore, due to the information asymmetry between organization and members, there are also differences between the organization and members in their perception of fault-tolerant environment (Wang 2017). Therefore, we assume عvro is the tolerance degree of virtual research organization to fault-tolerant environment, and $\varepsilon A$ is the tolerance degree of members to fault-tolerant environment, To some extent, $\varepsilon v r o$ and $\varepsilon A$ reflect the estimation of difficulties that virtual research organization and members may encounter in the sharing process of innovation failure knowledge. According to findings of $\mathrm{Xu}$ and Qiu (1999), the higher the value of cvro and $\varepsilon A$ is, the higher the tolerance degree of organization and its members to fault-tolerant environment. At this time, the expected utility of virtual research organization is:

$$
U(W v r o)=-\alpha+(1-\beta)\left(q x M^{a} \Delta e+\varepsilon v r o\right)
$$

The deterministic equivalent income of members is:

$$
\begin{aligned}
& W A=\alpha+\beta\left(q x M^{a} \Delta e+\varepsilon A\right)-b(\Delta e-r \varepsilon A)^{2} / 2-\rho \beta^{2} \sigma^{2} / 2 \\
& \quad=\alpha+\beta q x M^{a} \Delta e+(\beta+b r \Delta e) \varepsilon A-b \Delta e^{2} / 2-b r^{2} \varepsilon A^{2} / 2-\rho \beta^{2} \sigma^{2} / 2
\end{aligned}
$$

Thus, the incentive constraint can be expressed as:

$$
\alpha+\beta q x M^{a} \Delta e+(\beta+b r \Delta e) \varepsilon A-b \Delta e^{2} / 2-b r^{2} \varepsilon A^{2} / 2-\rho \beta^{2} \sigma^{2} / 2 \geq \overline{W A}
$$

Furthermore, it can be transformed into the following form:

$$
\text { (IC) } \Delta e=\beta q x M^{a} / b+r \varepsilon A
$$


The optimal incentive model of innovation failure knowledge sharing can be changed into the following forms:

$$
\begin{gathered}
\max _{\alpha, \beta, x, \Delta e} U(\text { Wvro })=-\alpha+(1-\beta)\left(q x M^{a} \Delta e+\varepsilon v r o\right) \\
\text { s.t. }\left\{\begin{array}{l}
(P C) \quad \alpha+\beta q x M^{a} \Delta e+(\beta+b r \Delta e) \varepsilon A-b \Delta e^{2} / 2-b r^{2} \varepsilon A^{2} / 2-\rho \beta^{2} \sigma^{2} / 2 \geq \overline{W A} \\
(I C) \quad \Delta e=\beta q x M^{a} / b+r \varepsilon A
\end{array}\right.
\end{gathered}
$$

Take formula (22) into formula (23) and obtain:

$$
\begin{gathered}
\max _{\beta} U(\text { Wvro })=\beta(\varepsilon A-\varepsilon v r o)+\varepsilon v r o+q x M^{a} r \varepsilon A-\rho \beta^{2} \sigma^{2} / 2-\overline{W A} \\
-\beta^{2} q^{2} x^{2} M^{2 a} / 2 b+\beta q^{2} x^{2} M^{2 a} / b
\end{gathered}
$$

Calculating the first derivative of $\beta$ with respect to formula (25) and obtain:

$$
(\varepsilon A-\varepsilon v r o)-\rho \beta \sigma^{2}-\beta q^{2} x^{2} M^{2 a} / b+q^{2} x^{2} M^{2 a} / b=0
$$

The optimal incentive coefficient $\beta^{* *}$ is:

$$
\beta^{* *}=\left[b(\varepsilon A-\varepsilon v r o)+q^{2} x^{2} M^{2 a}\right] /\left(b \rho \sigma^{2}+q^{2} x^{2} M^{2 a}\right)
$$

Furthermore, the following result is obtained:

$$
\Delta e^{* *}=\left[q^{3} x^{3} M^{3 a}+b(\varepsilon A-\varepsilon v r o) q x M^{a}\right] /\left(b \rho \sigma^{2}+q^{2} x^{2} M^{2 a}\right)+r \varepsilon A
$$

\section{Result analysis and discussion}

\subsection{Without considering the negative effect of fault-tolerance environment}

According to the results of formula (16), the first derivative of the parameters $q, b$, $\rho \sigma^{2}$ and $x$ is calculated for formula (16) respectively, and the following results are obtained:

$$
\begin{aligned}
& \partial \beta^{*} / \partial q=2 q x^{2} M^{2 a} b \rho \sigma^{2} /\left(b \rho \sigma^{2}+q^{2} x^{2} M^{2 a}\right)^{2}>0 \\
& \partial \beta^{*} / \partial b=-\rho \sigma^{2} q^{2} x^{2} M^{2 a} /\left(b \rho \sigma^{2}+q^{2} x^{2} M^{2 a}\right)^{2}<0 \\
& \partial \beta^{*} / \partial \rho \sigma^{2}=-b q^{2} x^{2} M^{2 a} /\left(b \rho \sigma^{2}+q^{2} x^{2} M^{2 a}\right)^{2}<0 \\
& \partial \beta^{*} / \partial x=2 x q^{2} M^{2 a} b \rho \sigma^{2} /\left(b \rho \sigma^{2}+q^{2} x^{2} M^{2 a}\right)^{2}>0
\end{aligned}
$$

According to formulas (29) and (32), $\beta^{*}$ is an increasing function of parameters $q$ and $x$. According to the results of formulas (30) and (31), $\beta^{*}$ is a decreasing function of parameters $b$ and $\rho \sigma^{2}$. Therefore, it can be concluded as follows: 
Theorem 1 Without considering the negative effect of fault-tolerant environment, the optimal incentive coefficient of virtual research organization for innovation failure knowledge sharing will increase with the improvement of the shareable rate of innovation failure knowledge and the transformation ability of innovation failure knowledge of members, and decrease with the increase of sharing cost coefficient of innovation failure knowledge and risk aversion degree of members.

Specifically, when the members of virtual research organization have more shareable innovation failure knowledge, the organization should give more incentive intensity to the members. Innovation failure knowledge is an important source to enhance an organization's innovation ability. Through learning of innovation failure knowledge, members can effectively reduce the probability of failure in the innovation process, so as to improve the overall innovation income of virtual research organization. The higher knowledge transformation ability of members is, the more they can transform their innovation failure experience into the knowledge form that can be stored, spread and shared. Optimal incentive coefficient of innovation failure knowledge sharing is also affected by the sharing cost. The higher the sharing cost is, the lower the sharing incentive intensity. This result further validates Wang's (2017) findings that the sharing cost is the main factor affecting the realization of failure knowledge sharing among members of the R\&D organization. The reason is that the high sharing cost of innovation failure knowledge means that virtual research organization needs to invest too much incentive investment to realize innovation failure knowledge sharing, but the organization pursues economic benefits, and the high sharing cost will further inhibit organization's incentive. The greater the risk aversion degree of organization members, the lower members' willingness to share innovation failure knowledge is. This finding further leads to the lack of incentive willingness of organizations, and is a unique manifestation of innovation failure knowledge sharing of members in the context of innovation failure. The possible reasons are: on the one hand, the existence of sharing cost will make members pay attention to their own interests. On the other hand, more importantly, members choose risk aversion because they are not willing to show their own innovation failure to the organization and other members, resulting in others' question their own innovation ability, thus affecting their position in the virtual research organization and the allocation of $R \& D$ resources.

\subsection{Considering the negative effect of fault-tolerance environment}

According to the results of formula (27), the first derivatives of parameters $\varepsilon v r o$ and $\varepsilon A$ are calculated for formula (27), and the following results are obtained:

$$
\begin{gathered}
\partial \beta^{* *} / \partial \varepsilon A=b /\left(b \rho \sigma^{2}+q^{2} x^{2} M^{2 a}\right)>0 \\
\partial \beta^{* *} / \partial \varepsilon v r o=-b /\left(b \rho \sigma^{2}+q^{2} x^{2} M^{2 a}\right)<0
\end{gathered}
$$


It can be seen from formulas (33) and (34) that $\beta^{* *}$ is an increasing function of parameter $\varepsilon A$ and a decreasing function of parameter $\varepsilon v r o$. Therefore, it can be concluded as follows:

Theorem 2 Considering the negative effect of fault-tolerant environment, the optimal incentive coefficient of virtual research organization for innovation failure knowledge sharing of members will decrease with the improvement of the organization's estimation of tolerance degree to fault-tolerant environment. The organization thinks that the better the fault-tolerant environment is, the smaller the optimal incentive coefficient is. When the members' estimation of tolerance degree to fault-tolerant environment is increased, the better the fault-tolerant environment is, the higher the optimal incentive coefficient is.

Specifically, when the organization's estimation of tolerance to fault-tolerant environment $\varepsilon v r o$ is large, it indicates that the organization believes that there is a good fault-tolerant environment within the virtual research organization. Members can positively examine the innovation failure results, through the transformation and sharing of innovation failure knowledge, and then improve the overall innovation ability of virtual research organization. The increment of innovation income will be considered by the organization as a result of a good fault-tolerant environment, not determined by the sharing efforts of innovation failure knowledge of the members themselves. Therefore, the virtual research organization will reduce the incentive intensity of innovation failure knowledge sharing. When the value of evro is small, the organization thinks that there is a poor fault-tolerant environment in current, the increment of innovation income generated by innovation failure knowledge sharing is more from the sharing efforts of innovation failure knowledge of members. Therefore, virtual research organization will further stimulate members' willingness to knowledge sharing and improve the sharing efforts of knowledge by enhancing the incentive intensity of innovation failure knowledge sharing.

When the members' estimation of tolerance to fault-tolerant environment $\varepsilon A$ is large, it means that members think that there is a good fault-tolerant environment for innovation within the virtual research organization. Members' will not be questioned by the organization and other members about their innovation ability because of innovation failure knowledge transformation and sharing of their own experience (Lu et al. 2020), but also get more innovation incomes and sharing rewards from the organization due to the innovation failure knowledge sharing. Therefore, members will pay more innovation failure knowledge and higher sharing efforts, and organization will pay more incentives of innovation failure knowledge sharing. When the value of $\varepsilon A$ is small, members may be more worried about the threat of their position and $R \& D$ resource allocation in virtual research organization due to the innovation failure knowledge sharing, which will reduce their efforts of knowledge sharing, and thus reduce the incentive intensity of the organization.

According to the results of formulas (16) and (27), ignoring the negative effect of fault-tolerant environment, the optimal incentive coefficient of innovation 
failure knowledge sharing is $\beta^{*}=q^{2} x^{2} M^{2 a} /\left(b \rho \sigma^{2}+q^{2} x^{2} M^{2 a}\right)$. Considering the negative effect of fault-tolerance environment, the optimal incentive coefficient is $\beta^{* *}=\left[b(\varepsilon A-\varepsilon v r o)+q^{2} x^{2} M^{2 a}\right] /\left(b \rho \sigma^{2}+q^{2} x^{2} M^{2 a}\right)$. The difference lies in whether virtual research organization's and its members' estimation of tolerance to faulttolerant environment is equally. When $\varepsilon A \neq \varepsilon v r o$, because of the difference about estimation of tolerance to fault-tolerant environment between organization and members, it is necessary to readjust the incentive intensity to further promote the innovation failure knowledge sharing among members in virtual research organization. According to the findings of Theorem 2, the optimal incentive coefficient is negatively related to organization's estimation of tolerance to fault-tolerant environment, and positively related to members' estimation of tolerance to faulttolerant environment. This is a novel finding of this study, specifically, when $\varepsilon v r o$ is determined, the better members' estimation of tolerance to fault-tolerant environment, and the larger $\varepsilon A$ is, the more incentive intensity of innovation failure knowledge sharing should be increased, and more innovation failure experiences of members should be transformed and shared. On the contrary, the smaller $\varepsilon A$ is, members think that there is a certain risk in the sharing process of innovation failure knowledge, and they are not willing to share more innovation failure knowledge. At this time, the organization's incentive means have no obvious influence on the member's knowledge sharing effort, so the organization should reduce the incentive.

\subsection{Case study}

To more intuitively reflect the difference of the optimal incentive level of virtual research organization and the sharing efforts of innovation failure knowledge of members, taking Collaborative Innovation Center of Textile and Garment Industry (CICTGI) in Henan of China as a case study, the results of the theoretical model are simulated and verified.

CICTGI was founded in October 2012, gathering a group of top talents in the textile and garment industry, forming a high-level collaborative innovation team, which is committed to the research and development of functional fiber materials, the design and manufacturing of high-end textile equipment, and the research and development of key technologies in the processing of high-end fabrics, clothing and industrial textiles. Members of the collaborative innovation center include 16 universities and enterprises, including Zhongyuan University of Technology, Hi-Tech Heavy Industry Co., Ltd., Xinxiang Bailu Investment Group Co., Ltd., Jiangnan University, Manchester University, YERAD Clothing, Shanghai Haochang Mechanical Electrical Equipment Co., Ltd., Shandong Ruyi Technology Group Co., Ltd., etc. It can be seen that CICTGI has formed a R\&D network without geographical boundary, which has typical characteristics of virtual research organization. In addition, in order to create an innovation atmosphere that encourages innovation and tolerates failures, the collaborative innovation center has reformed relevant management regulations in recent years, expecting to give more understanding and toleration to the failures that may occur in the normal innovation process, and to change the negative 
effect of the original fault-tolerant environment that only depends on the results and does not care about the process, and only on the success or failure.

To obtain the relevant information about innovation failure knowledge sharing of the case study, 16 members of CICTGI were investigated by means of online questionnaire survey and telephone interview from August to September 2019. The main content includes the sharing willingness, cost, stock, shareable rate of innovation failure knowledge and risk tendency of members. The mean value of the acquired data was processed. Furthermore, combined with the parameter attributes of the theoretical model, some survey data were transformed. According to the actual situation of the case study, the initial values of the model parameters were set as: $b=0.4$. $q=0.6, x M^{a}=1, \rho \sigma^{2}=1$. Taking the initial value of the above parameters into formula (27), the optimal incentive coefficient $\beta$ of virtual research organization is obtained, that is:

$$
\beta^{* *}=0.526 \times(\varepsilon A-\varepsilon v r o)+0.474
$$

Using Matlab R2015b software to simulate the data, the change of the optimal incentive coefficient $\beta$ of virtual research organization is obtained under the two situations of whether the impact of fault-tolerant environment is considered or not.

It can be seen from Fig. 1 that when considering the negative effect of faulttolerant environment, the incentive level of innovation failure knowledge sharing decreases with the increase of the organization's estimation of tolerance degree to fault-tolerant environment, and increases with the increase of members' estimation of tolerance degree, which is also verified in case study. For example, the

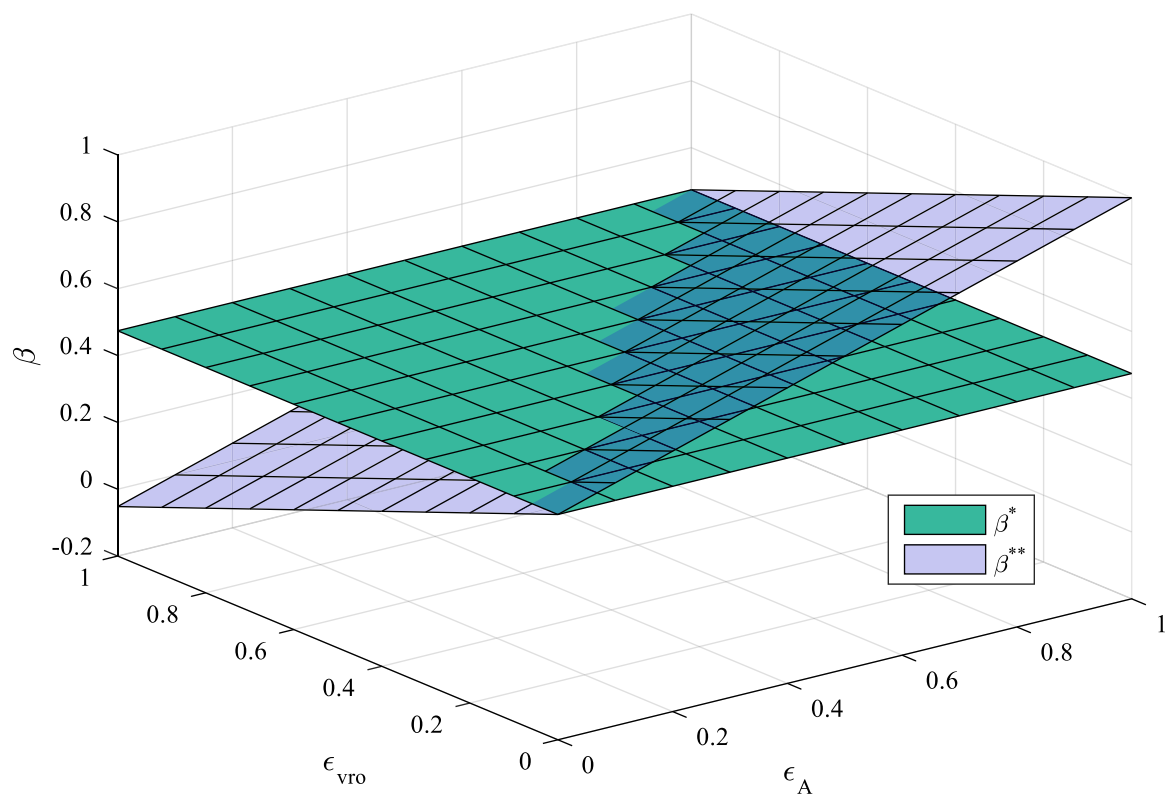

Fig. 1 The change of the optimal incentive coefficient of virtual research organization 
implementation of the project "Complete Set of Technology and Equipment for the Preparation of Superfine Spandex" is not smooth enough. R\&D discontinuation caused by failure of experiment often occurs, but in a relatively loose innovation atmosphere, the members pay more attention to the investigation of failure causes, but seldom publicize that a member will be punished for failure. On the contrary, CICTGI encourages the sharing of failure experience among members through material incentive, reputation incentive and other incentive ways, not only to find out the reasons for the failure of the experiment more quickly, but also to help other members get the knowledge transformed from the failure experience, reducing the probability of repeated failure. The above results are further validation of Theorem 2. Furthermore, when $\varepsilon A>\varepsilon v r o$, the incentive level of innovation failure knowledge sharing will gradually increase. When $\varepsilon A=\varepsilon v r o$, virtual research organization and its members have the same estimation of tolerance degree to fault-tolerance environment, and the incentive level will remain unchanged.

The initial value of model parameter is brought into formula (29), and the following relation function is obtained:

$$
\Delta e^{* *}=0.316 \times(\varepsilon A-\varepsilon v r o)+0.284+r \varepsilon A
$$

It can be seen that the level of innovation failure knowledge sharing efforts $\Delta e$ is positively related to the member's estimate of tolerance degree to innovation fault tolerance environment $\varepsilon A$, The better members perceive the tolerance degree of fault-tolerant environment, the better they can promote their own sharing efforts of innovation failure knowledge. When the impact of fault-tolerant environment on the

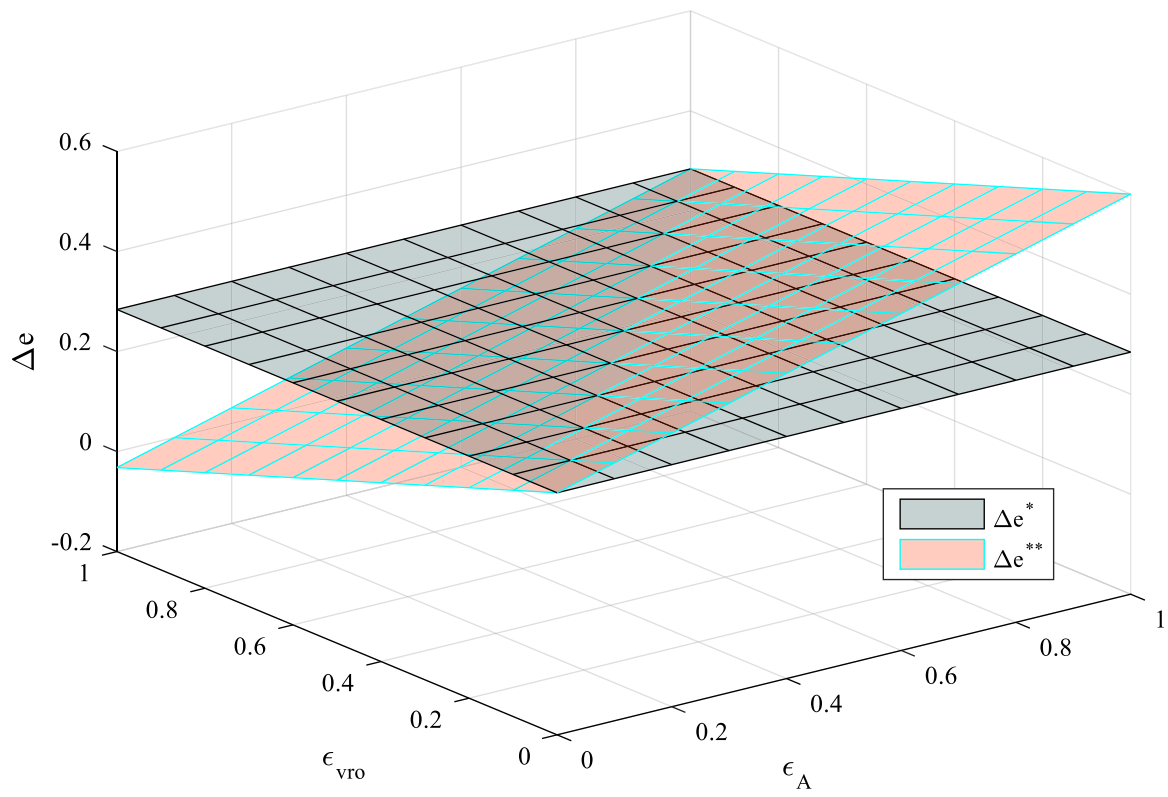

Fig. 2 The change of innovation failure knowledge sharing efforts of virtual research organization 
sharing efforts of innovation failure knowledge $r=0$, the change of sharing efforts of innovation failure knowledge $\Delta e$ is shown in Fig. 2.

It can be seen from Fig. 2 that the change of sharing efforts of members $\Delta e$ is similar to the change of optimal incentive coefficient $\beta$, that is to say, the knowledge sharing efforts of members decreases with the increase of the organization's estimate of tolerance degree to fault-tolerant environment, and increases with the increase of the member's estimate of tolerance degree to fault-tolerant environment.

When $r \neq 0, r$ is independent of the organization's incentive level. However, there is a positive correlation between the knowledge sharing efforts of members and the organization's incentive level. The negative effect of fault-tolerant environment will further affect the observation of members' knowledge sharing efforts. Therefore, the key to improve the sharing willingness of innovation failure knowledge of CICTGI's member lies in creating an innovation atmosphere that encourages innovation and tolerates failure.

Specifically, when $\varepsilon A>\varepsilon v$ ro, the knowledge sharing efforts of members is higher, they will actively share innovation failure knowledge and are willing to bear the corresponding risk of knowledge sharing, the organization should increase its incentive compensation. When $\varepsilon A<\varepsilon v r o$, the knowledge sharing efforts of members without considering the negative effect of fault-tolerant environment is higher than that with considering the negative effect of fault-tolerant environment. At this time, the sharing incentive of virtual research organization cannot promote the knowledge sharing efforts of members, so the organization should reduce the incentive.

It should be noted that, If $\varepsilon v r o$ is too large, the organization will reduce the incentive level of innovation failure knowledge sharing, if a member of virtual research organization finds out this situation, it may have social loafing effect (Vveinhardt and Banikonyte 2017), and is not conducive to the innovation failure knowledge sharing of the whole organization. Therefore, for the improvement of the incentive mechanism, CICTGI should timely adjust the incentive intensity according to the estimation of tolerance degree to fault-tolerant environment of itself and its members; on the other hand, it should also strengthen the correct understanding of faulttolerant environment of itself and its members.

\section{Conclusions}

In view of the process of innovation failure knowledge sharing among the members of virtual research organization, considering the risk aversion degree of the members and the negative effect of fault-tolerant environment, the incentive model of innovation failure knowledge sharing of virtual research organization was constructed in this study. Through the theoretical analysis and case study of the incentive model, the following conclusions were drawn: (1) the optimal incentive coefficient of virtual research organization for innovation failure knowledge sharing increases with the improvement of the members' shareable rate of innovation failure knowledge and the members' transformation ability of innovation failure knowledge, and decreases with the increase of members' sharing cost coefficient and members' risk aversion 
degree. (2) Considering the negative effect of fault-tolerant environment, the optimal incentive coefficient of virtual research organization for innovation failure knowledge sharing decreases with the increase of tolerance degree of organization to faulttolerant environment, and increases with the increase of tolerance degree of organization members to fault-tolerant environment. (3) The virtual research organization should make the corresponding revision of the sharing incentive intensity according to the information it has, to further reduce the risk of knowledge sharing incentive and improve the overall innovation income of the organization.

This study presents the following management implications: (1) in the practice of innovation failure knowledge management, through the establishment of a good reward-and-punishment mechanism and supervision mechanism, the knowledge sharing behavior of the members in virtual research organization is strengthened promptly, which will effectively promote the members to adopt the sharing and cooperation strategy, and greatly reduce the free-riding behavior. (2) Virtual research organization should manage the tolerance degree of its members to the fault-tolerant environment, and improve the fault-tolerant environment within the organization. In the design of incentive contract, the interaction between fault-tolerant environment and innovation failure knowledge sharing rate, transformation ability, sharing cost and risk aversion degree are comprehensively considered, and appropriate incentive coefficient is selected to maximize the sharing behavior of organization members.

In addition, this study focuses on the impact of the negative effort of fault-tolerant environment on the incentive of innovation failure knowledge sharing in virtual research organization. However, in the case of previous innovation failure, the incentive of innovation failure knowledge sharing is not only closely related to external environmental conditions, but also closely related to the individual characteristics of members, such as the cost of innovation failure of members, the position of members in virtual research organization and other factors. Therefore, in the follow-up study, we can further consider the influence of individual characteristics of members in virtual research organization on the incentive intensity of knowledge innovation failure sharing.

Funding This study was supported by the National Social Science Fund of China (Grant No. 18CJL006), Science and Technology Innovation Talent Support Plan in Colleges and Universities of Henan, China, in 2020 (Humanities and Social Sciences) (Grant No. 2020-cx-019), Humanities and Social Sciences Research Project of the Ministry of Education of China (Grant No. 20YJC630171), Humanities and Social Sciences Research General Project in Henan Province of China (Grant No. 2021-ZZJH-414).

Open Access This article is licensed under a Creative Commons Attribution 4.0 International License, which permits use, sharing, adaptation, distribution and reproduction in any medium or format, as long as you give appropriate credit to the original author(s) and the source, provide a link to the Creative Commons licence, and indicate if changes were made. The images or other third party material in this article are included in the article's Creative Commons licence, unless indicated otherwise in a credit line to the material. If material is not included in the article's Creative Commons licence and your intended use is not permitted by statutory regulation or exceeds the permitted use, you will need to obtain permission directly from the copyright holder. To view a copy of this licence, visit http://creativecommons.org/licen ses/by/4.0/. 


\section{References}

Adler TR, Zirger BJ (1998) Organizational learning: implications of a virtual research and development organization. Am Bus Rev 16(2):51-60

Albers S, Wohlgezogen F, Zajac EJ (2016) Strategic alliance structures: an organization design perspective. J Manage 42(3):582-614

Al-Haddad L, Whittington M (2019) The impact of corporate governance mechanisms on real and accrual earnings management practices: evidence from Jordan. Corp Gov-Int J Bus Soc 19(6):1167-1186

Almeida A, Tereso A, Faria J, Ruão T (2018) Knowledge sharing in industrialization project management practices. In: Rocha Á, Adeli H, Reis LP, Costanzo S (eds) Trends and advances in information systems and technologies. WorldCIST'18 2018. Advances in Intelligent Systems and Computing, Springer, Cham, vol 745, pp 53-62

Amankwah-Amoah J, Boso N, Antwi-Agyei I (2018) The effects of business failure experience on successive entrepreneurial engagements: an evolutionary phase model. Group Organ Manage 43(4):648-682

Assaad R, El-Adaway IH (2020) Enhancing the knowledge of construction business failure: a social network analysis approach. J Constr Eng M 146(6):04020052

Cannon MD, Edmondson AC (2001) Confronting failure: antecedents and consequences of shared beliefs about failure in organizational work groups. J Organ Behav 22(2):161-177

Carmeli A, Dothan A (2017) Generative work relationships as a source of direct and indirect learning from experiences of failure: implications for innovation agility and product innovation. Technol Forecast Soc 119:27-38

Chang SG, Ahn JH (2005) Product and process knowledge in the performance-oriented knowledge management approach. J Knowl Manag 9(4):114-132

Chen G, Zhou Q, Liu W (2017) Organizational learning from experience: current status in multilevel perspective, integration model and future direction. Nankai Bus Rev Int 8(2):122-157

Chen KQ, Zhang CX, Wu YY (2019) The innovative way of virtual research organization in the era of E-science. High Educ Explor 2:5-12

Choi SY, Kang YS, Lee H (2008) The effects of socio-technical enablers on knowledge sharing: an exploratory examination. J Inform Sc 34(5):742-754

Connell J, Kriz A, Thorpe M (2014) Industry clusters: an antidote for knowledge sharing and collaborative innovation? J Knowl Manag 18(1):137-151

Dai YJ, Hu YF (2011) Research on the characteristics and mechanism of trust relationship in virtual research organization. Sci Techn Prog Policy 28(24):13-16

Danneels E, Vestal A (2020) Normalizing vs. analyzing: drawing the lessons from failure to enhance firm innovativeness. J Bus Ventur 35(1):105903

Davenport S, Daellenbach U (2011) Belonging to a virtual research centre: exploring the influence of social capital formation processes on member identification in a virtual organization. Brit $\mathrm{J}$ Manage 22(1):54-76

Dawes SS, Gharawi MA, Burke GB (2012) Transnational public sector knowledge networks: knowledge and information sharing in a multi-dimensional context. Gov Inform Q 29:112-120

Deichmann D, Ende JVD (2013) Rising from failure and learning from success: the role of past experience in radical initiative taking. Organ Sci 25(3):670-690

Del Baldo M, Baldarelli MG (2017) Renewing and improving the business model toward sustainability in theory and practice. Int J Corp Soc Resp 2(1):3

Desai V (2015) Learning through the distribution of failures within an organization: evidence from heart bypass surgery performance. Acad Manage J 58(4):1032-1050

Dickson PH, Weaver KM (2011) Institutional readiness and small to medium-sized enterprise alliance formation. J Small Bus Manage 49(1):126-148

Edmondson AC (2011) Strategies for learning from failure. Harvard Bus Rev 89(4):48-55

Friedrich J, Becker M, Kramer F, Wirth M, Schneider M (2020) Incentive design and gamification for knowledge management. J Bus Res 106:341-352

Ghobadi S (2015) What drives knowledge sharing in software development teams: a literature review and classification framework. Inform Manag 52(1):82-97

Hao XL, Tu YQ, Chen X, Liu YR (2019) Recalling the painful experience? Impact of emotional costs on entrepreneurial failure learning. R\&D Manage (in Chinese) 31(4):27-39 
Jiang G, Xu Y (2020) Tacit knowledge sharing in IT R\&D teams: nonlinear evolutionary theoretical perspective. Inform Manag 57(4):103211

Kim JY, Miner AS (2007) Vicarious learning from the failures and near-failures of others: evidence from the US commercial banking industry. Acad Manage J 50(3):687-714

Lin S, Yamakawa Y, Li J (2019) Emergent learning and change in strategy: empirical study of Chinese serial entrepreneurs with failure experience. Int Entrep Manag J 15(3):773-792

Liu G, Ye J, Argyres C (2020) Modeling and simulation of the knowledge growth process among new energy technology firms in the distributed innovation network. Dyna-Bilbao 95(1):54-60

Liu Y, Li Y, Shi LH, Liu T (2017) Knowledge transfer in buyer-supplier relationships: the role of transactional and relational governance mechanisms. J Bus Res 78:285-293

Liu Z, Shang J, Lai M (2015) Incentive mechanism for knowledge sharing in e-commerce service supply chain: complementarity, integration and risk attitude. J Electron Commer Re 16(3):175-193

Lloyd R, Mertens D (2018) Expecting more out of expectancy theory: history urges inclusion of the social context. Int Manag Rev 14(1):28-43

Lu JT, Ren LC, Zhang C, Liang MS, Stasiulis N, Streimikis J (2020) Impacts of feminist ethics and gender on the implementation of CSR initiatives. Filos-Sociol 31(1):24-33

Luo ZM, Zhou JZ, Zheng LP, Mo L, He YY (2010) A TFN-ANP based approach to evaluate Virtual Research Center comprehensive performance. Expert Syst Appl 37(12):8379-8386

Ma WW, Chan A (2014) Knowledge sharing and social media: altruism, perceived online attachment motivation, and perceived online relationship commitment. Comput Hum Behav 39:51-58

McGrath RG (1999) Falling forward: real options reasoning and entrepreneurial failure. Acad Manage Rev 24(1):13-30

Nan N (2008) A principal-agent model for incentive design in knowledge sharing. J Knowl Manag 12(3):101-113

Prester J, Jurić M (2019) Big data for product innovation in manufacturing: evidence from a large-scale survey. Teh Glasn 13(1):36-42

Raghuram S, Hill NS, Gibbs JL, Maruping LM (2019) Virtual work: bridging research clusters. Acad Manag Ann 13(1):308-341

Razmerita L, Kirchner K, Nielsen P (2016) What factors influence knowledge sharing in organizations? A social dilemma perspective of social media communication. J Knowl Manag 20(6):1225-1246

Rhaiem K, Amara N (2019) Learning from innovation failures: a systematic review of the literature and research agenda. Rev Manag Sci. https://doi.org/10.1007/s11846-019-00339-2

Safari A, Salehzadeh R, Panahi R, Abolghasemian S (2018) Multiple pathways linking environmental knowledge and awareness to employees' green behavior. Corp Gov-Int J Bus Soc 18(1):81-103

Shepherd DA (2003) Learning from business failure: propositions of grief recovery for the self-employed. Acad Manage Rev 28(2):318-328

Siemsen E, Balasubramanian S, Roth AV (2007) Incentives that induce task-related effort, helping, and knowledge sharing in workgroups. Manage Sci 53(10):1533-1550

Standing S, Standing C (2018) The ethical use of crowdsourcing. Bus Ethics 27(1):72-80

Vveinhardt J, Banikonytė J (2017) Managerial solutions that increase the effect of group synergy and reduce social loafing. Manage Organ 78(1):109-129

Wang M, Shao C (2012) Special knowledge sharing incentive mechanism for two clients with complementary knowledge: a principal-agent perspective. Expert Syst Appl 39(3):3153-3161

Wang PJ (2017) Evolutionary game analysis on knowledge sharing of failures among members of enterprise alliance. Inform Stud-Theory App 40(8):116-120

Weller AE (2017) Aligning responsible business practices: a case study. Bus Ethics 26(4):457-467

Wu Q, Zhang WG (2016) Choice strategies of incentive methods for large-scale knowledge sharing. J Syst Manag 25(3):498-505

Xie HF, Liu C (2014) Incentive mechanism of employees knowledge sharing based on multi-theory perspective. R\&D Manage 26(2):38-48

Xiong Z, Wang PJ, Zhao Y (2020) Re-innovation from failure, institutional environmental differences, and firm performance: evidence from China. Amfiteatru Econ 22(53):197-219

Xiong Z, Ye JM, Wang PJ, Yin Z (2016) Evolutionary game simulation on failure knowledge sharing among chemical enterprises. Chim Oggi 34(6B):13-19

Xu X, Qiu KH (1999) Study on impact of uncertain state of world to optimal contract in principal-agent theory. Chin J Manage Sci 7(2):62-66

Yu DD (2018) A study of supply chain knowledge sharing incentive and monitoring based on horizontal fairness preference. Ind Eng J 21(1):51-58 
Yu XY, Pu XL (2018) Chinese entrepreneurial failure: attribution, learning, and subsequent decisionmaking. J Manage Sci 31(4):103-119

Zhang F, Ye JM, Xie CZ (2019) Collusion-proof mechanism in compensation for failed generic technological innovation projects: based on information topology. Teh Vjesn 26(5):1410-1421

Zhang L, Zhang Z (2014) The effects of incentive mechanism on knowledge management performance in China: the moderating role of knowledge attributes. Proj Manag J 45(2):34-47

Zhang YL (2019) Fault tolerance mechanism and stimulating the spirit of protecting entrepreneurs. Soc Sci J 1:73-80

Publisher's Note Springer Nature remains neutral with regard to jurisdictional claims in published maps and institutional affiliations.

Zhuang Xiong is working as lecturer of Management Science and Engineering at the School of Business at Zhengzhou University of Aeronautics. He received his Doctoral Degree in Management Science and Engineering from Wuhan University of Technology, China in 2019. His research interest focus on failure management in the area of innovation and entrepreneurship, including failure knowledge management, impression management of failure-related stigma, behavior decision in re-innovation or re-entrepreneurship. Dr. Xiong's research has been supported by grants from Humanities and Social Sciences Research Project of the Ministry of Education in China.

Pengju Wang is currently working as an Assistant Professor at the School of Economics and Management at Zhongyuan University of Technology. She completed her Ph.D. in Business Management from Wuhan University of Technology, China in 2015 and was at the Zhongyuan University of Technology for five years. Dr. Wang's research focuses on studying complex systems, social networks and organizations through multi-agent modeling, including innovation ecosystem, entrepreneurial ecosystem, and repair of failure events in organizations. Her research has been supported by grants from National Social Science Fund of China, Science and Technology Innovation Talent Support Plan in Colleges and Universities of Henan, China.

Chengxia Wu is working as lecturer of Management Science and Engineering at the School of Business at Zhengzhou University of Aeronautics. She completed her Ph.D. in Management Science and Engineering from Tianjin University, China in 2016. Dr. Wu's research interest focus on Big Data marketing, supply chain management based on Internet of things. She is also an anonymous reviewer of Control Theory \& Applications, Operations Research and Management Science.

\section{Affiliations}

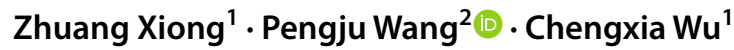

Zhuang Xiong

xiongzhuang@zua.edu.cn

Chengxia Wu

wucxhappy@126.com

1 School of Business, Zhengzhou University of Aeronautics, 450046 Zhengzhou, China

2 School of Economics and Management, Zhongyuan University of Technology, 450007 Zhengzhou, China 